\title{
Motivation Visual Analogue Scale
}

National Cancer Institute

\section{Source}

National Cancer Institute. Motivation Visual Analogue Scale. NCI Thesaurus. Code

C122997.

A scale for the subjective scoring of an individual's motivation that ranges from 1: Not at all motivated to 7: Extremely motivated. 